\title{
Article \\ Online Multi-Level Energy Management Strategy Based on Rule-Based and Optimization-Based Approaches for Fuel Cell Hybrid Electric Vehicles
}

\author{
Hamed Farhadi Gharibeh ${ }^{1,+(D)}$ and Meisam Farrokhifar $2, *,+(\mathbb{D}$ \\ 1 Faculty of Electrical Engineering, Sahand University of Technology, Tabriz 51335/1996, Iran; \\ h_farhadi@sut.ac.ir \\ 2 Center for Energy Science and Technology, Skolkovo Institute of Science and Technology, \\ 143026 Moscow, Russia \\ * Correspondence: m.farrokhi@skoltech.ru \\ + These authors contributed equally to this work.
}

check for

updates

Citation: Farhadi Gharibeh, H.;

Farrokhifar, M. Online Multi-Level

Energy Management Strategy Based

on Rule-Based and

Optimization-Based Approaches for Fuel Cell Hybrid Electric Vehicles.

Appl. Sci. 2021, 11, 3849. https:

//doi.org/10.3390/app11093849

Academic Editor: Rodolfo

Dufo-López

Received: 20 March 2021

Accepted: 20 April 2021

Published: 24 April 2021

Publisher's Note: MDPI stays neutral with regard to jurisdictional claims in published maps and institutional affiliations.

Copyright: (C) 2021 by the authors. Licensee MDPI, Basel, Switzerland. This article is an open access article distributed under the terms and conditions of the Creative Commons Attribution (CC BY) license (https:/ / creativecommons.org/licenses/by/ $4.0 /)$.

\begin{abstract}
This paper introduces an online multi-level energy management strategy (EMS) based on proposed rule-based and optimization-based approaches for fuel hybrid electric vehicles, including fuel cell, battery, and ultracapacitor systems. Our approach combines equivalent consumption minimization, state machine control, operational mode control, and fuzzy logic control methods. The proposed multi-level EMS reduces fuel consumption, enhances fuel cell operating time in a high-efficiency range, reduces battery power fluctuations, and improves maintaining the battery state of charge (SOC). The proposed EMS is compared with the optimized-fuzzy logic control (Opt-FLC) method. The results show a reduction in fuel consumption, battery power fluctuations, and the SOC difference between the start and end of the driving cycle, compared to Opt-FLC. Hence, fuel economy improvement and lifetime enhancement of hybrid energy storage system are the significant outcomes of new proposed multi-level EMS.
\end{abstract}

Keywords: combined efficiency; energy management strategy; fuzzy logic control; operational mode control; fuel consumption; power fluctuation

\section{Introduction}

Fuel consumption reduction and tailpipe emission are the main objectives of the transition to the electrified transportation industry. Fuel cell vehicles (FCVs) have a high superiority in the development of transportation electrification. Pure fuel cell vehicles have main drawbacks, which encourage designers to design FCVs with the support of battery, ultracapacitor (UC), photovoltaic, or hybrid configurations. This hybrid configuration incurs additional complexity to the power-train control system, which means the energy storage systems (ESSs) should be optimally controlled. Hence, the online energy management strategy (EMS) in the fuel cell hybrid electric vehicles (FCHEVs) is a critical point in the electrification of the transportation industry [1-3].

The slow dynamic response of fuel cells (FCs) and its incapability of regenerative braking energy capture are the main drawbacks of FCVs, making them equipped with ESSs in the electrified transportation industry. However, none of the ESSs has high power and energy density at the same time. The batteries have a high energy density, and the UCs have a high power density. As a result, the combination of battery and UC can supply the vehicle's required power in multi-second peaks. In regenerative braking modes, the battery's low power density does not allow it to contribute completely to receiving the energy generated by the brake, but the UCs can capture this energy. Considering the above discussion, the combination of ESSs improves the performance of the FCHEVs [4-8].

The proton exchange membrane fuel cell (PEMFC) is the most promising FC type for application in the electrified transportation industry. The PEMFC has high efficiency, 
low operating temperature, high power density, nearly zero-emission, and a relatively fast startup $[9,10]$. Among the possible state-of-the-art hybridized architectures of the ESSs, the FC/battery/UC structure is the most attractive configuration [11]. This HESS structure has the lowest hydrogen consumption cost and electricity price compared to the FC/battery and FC/UC structures [12], and a reliable energy management strategy is needed to maximize the mentioned advantages.

The energy management strategies encompass rule-based (deterministic, fuzzy logic control) and optimization-based (real-time, global) approaches. The global optimizationbased method requires prior knowledge of an entire driving cycle to minimize the cumulative fuel consumption. The real-time optimization-based approaches eliminate the requirement to obtain prior knowledge by reducing global optimization problems into a succession of local optimization problems. But the global optimal point can differ from a locally optimal point. For instance, the equivalent consumption minimization strategy (ECMS) outperforms the other real-time methods, but the optimal point in global methods might differ $10 \%$ in comparison with ECMS [13,14].

The online rule-based strategies have lower implementation costs, lower occupied memory space, and higher determination speed, but engineering experiences affect these strategies' performance. Fuzzy logic control (FLC), wavelet-FLC, adaptive-FL, fuzzy logic on-off power control, state machine control (SMC), operational mode control (OMC), power follower, on-off power control, and modified power follower are based on the rule-based EMS [15].

The fuzzy logic performance is evaluated through the following studies. In [16], a triple fuzzy logic controller based on data fusion has been presented to the online energy management of FCHEV. The genetic algorithm has been used to optimize the membership function parameters of FLC for three driving cycles. Moreover, the probabilistic support vector machine method has been applied to detect various driving conditions. However, driving conditions have only been categorized into three groups. Moreover, the authors have selected the battery and UC states empirically.

For investigation multi-level methods, the following features are compared. The authors in [17] have presented a fuzzy-back stepping control strategy for battery/UC based on real-time evaluation of six on-off operational modes to reduce battery power fluctuations. The simulation platform via Cruise and MATLAB software has been presented to validate the results [18]. The authors in [19] have presented a fuzzy logic control method combined with genetic algorithm for FCHEV in a simulation platform of ADVISOR. The genetic algorithm has been used to optimize the membership function parameters of FC output power to reduce equivalent hydrogen consumption and improve battery lifetime [19].

In the field of multi-level EMS methods, the authors in [20] have proposed an EMS based on SMCS and ECMS for FC/UC hybrid tramway to increase the operating time of FC in a high-efficiency range and decrease the FC power fluctuations. The combination of SMCS with droop control has been presented in [21] to coordinate multiple ESSs based on their natural characteristics, aiming to enhance high-efficiency performance range and satisfy fast changes in the demand power.

Generally, in the reviewed energy management strategies [16-21], the HESS energy efficiency, battery or UC state division, and movement conditions of the vehicle have not been analyzed mathematically. Moreover, the fluctuations of FC and battery power can be reduced efficiently, and driving conditions can be detected without comparing driving cycles. To address the mentioned problems, the following contributions are proposed in this paper:

- The vehicle movement states are formulated based on the vehicle's speed, acceleration, and power.

- $\quad$ Battery and UC state divisions are presented based on the mathematical formulation of the proposed combined energy efficiency concept.

- $\quad$ FLC and OMC methods are used to reduce FC and battery power fluctuations. Moreover, the operational modes of FC are selected based on efficiency and ECM concept. 
- Finally, an online multi-mode energy management strategy based on SMC, FLC, ECM, and OMC methods is presented for power management of the FC/battery/UC vehicle.

The rest of the paper is organized as follows. In Section 2, the framework of hybrid energy storage systems is presented. The proposed EMS, which includes SMC, ECM, FLC, and OMC power contribution, is proposed in Section 3. The MATLAB simulation results of the proposed EMS are given in Section 4. Finally, the conclusions are discussed in Section 5.

\section{Hybrid Energy Storage System}

The HESS of FCHEVS which includes FC, battery, and UC is studied in this paper. It is necessary to analyze each source's model accurately to ensure the proposed EMS's optimal performance.

\subsection{PEMFC System}

The mathematical model of PEMFC is essential to the power management of HESSs. The efficiency equation of PEMFC based on its dynamic model is shown by (1) [22].

$$
\eta_{f c}=\frac{V_{F C} i_{f c}-P_{a u x}}{M_{H 2} \Delta H}
$$

where $M_{H 2}$ and $\Delta H$ indicate the Molar mass and the hydrogen enthalpy change, respectively. Finally, the hydrogen consumption in PEMFC system is formulated by (2) in which $\eta_{d c}$ and $\rho_{H 2}$ represent the DC-DC converter efficiency and hydrogen chemical energy density, respectively.

$$
m_{H 2}=\int_{0}^{t}\left[\frac{V_{F C}(t) i_{F C}(t)}{\eta_{d c}(t) \rho_{H 2}}\right] d t
$$

\subsection{Lead-Acid Battery}

The dynamic performance of the battery depends on open circuit voltage $\left(U_{o c}\right)$, internal resistance $\left(R_{B a t}\right)$, and state of charge $(S O C)$. The battery state of charge is calculated by (3) [23]:

$$
\operatorname{SOC}(t)=S O C_{0}-\int_{0}^{t} \frac{I_{B a t}(t)}{E_{B a t}} d t
$$

where $E_{B a t}$ is the battery maximum capacity, and $S O C_{0}$ is the initial state of charge. The battery charge and discharge efficiency are different from each other, and can be formulated based on (4) for lead-acid battery:

$$
\left\{\begin{array}{l}
\eta_{\text {dis }}=\frac{1+\sqrt{1-\frac{4 R_{\text {dis }} P_{B a t}}{U_{o c}^{2}}}}{2} \\
\eta_{\text {chg }}=\frac{2}{1+\sqrt{1+\frac{4 R_{c h g} P_{B a t}}{U_{o c}^{2}}}}
\end{array}\right.
$$

where $R_{\text {chg }}$ and $R_{\text {dis }}$ indicate the battery resistance on charge and discharge mode, respectively [24].

\subsection{Ultracapacitor}

UC plays an important role in supplying peak demand power during acceleration and absorbing the regenerative braking energy. High power density, continuous operation, and high charge/discharge efficiency make the UC superior over FC and battery. Like the battery, the UC's behavior is also described using a dynamic model in which the voltage discharge ratio $(V D R)$ of the UC and efficiency are considered. The $V D R$, UC consumable 
energy $\left(W_{u c}\right)$, and UC maximum power $\left(P_{u c, M a x}\right)$ are the essential parameters to detect the UC working condition. These parameters are formulated using (5)-(7) [25].

$$
\begin{gathered}
V D R=\frac{V_{t}}{V_{M}} \times 100 \\
W_{u c}=W_{M}\left(\frac{V D R}{100}\right)^{2} \\
P_{u c, M a x}=\frac{V_{t}^{2}}{4 \times R_{s} \times \text { mass }_{u c}}
\end{gathered}
$$

where $V_{t}$ is UC output volatge; $V_{M}$ indicates the maximum voltage of the UC; $W_{M}$ presents maximum energy of the UC; $R_{S}$ is series resistance of UC; and mass $s_{u c}$ is the mass of UC. Moreover, the UC efficiency in charge or discharge mode has different values. Therefore, the charge and discharge efficiency of UC are formulated based on (8) [25].

$$
\left\{\begin{array}{l}
\eta_{u c d}=\frac{V_{t} \cdot i_{t}}{V_{C} \cdot i_{C}}=\frac{\left(V_{C}-i_{t} \cdot R_{S}\right) i_{t}}{V_{C}\left(i_{t}+i_{L}\right)} \\
\eta_{u c c}=\frac{V_{C} \cdot i_{C}}{V_{t} \cdot i_{t}}=\frac{V_{C}\left(i_{t}-i_{L}\right)}{\left(V_{C}+i_{t} \cdot R_{S}\right) i_{t}}
\end{array}\right.
$$

where $V_{C}$ and $i_{C}$ represent the internal voltage and current of the UC cells; $i_{L}$ and $i_{t}$ indicate the linkage current and terminal current of the UC, respectively.

\section{Proposed Energy Management Strategy}

FCHEVs are considered an appropriate alternative for internal combustion engine vehicles, and researchers continue their studies to improve hybrid energy storage performance. In this article, the state machine control ideas, fuzzy logic control, the equivalent consumption minimization strategy, and the operational mode control strategy are used to optimal management of the HESS in FCHEVs, as shown in Figure 1.

In the first level of the proposed EMS, the FCHEV movement states, battery SOC, and UC VDR have been identified. The vehicle state movements (VSM) are divided into 5 states; the battery SOC range is divided into 4 states, and the UC VDR range is divided into 4 states. In the second step, the fuzzy logic control strategy was designed based on the operation function of vehicle state movement, demand power, battery SOC, and UC VDR to calculate the FC and battery output power. In the next step, the hydrogen consumption ratio $(H C R)$ curve is obtained using the simulation results to perform equivalent consumption minimization theory. Then HCR and its dispersion indices are used to select high-efficiency operation points all over the FC operating range. Finally, FC and battery's operational modes have been applied to the proposed EMS to implement the operational mode control strategy.

\subsection{Proposed State Machine Control}

The SMCS is a deterministic rule-based method that can be used for vehicle movement condition detection, battery SOC division, and UC VDR classification. This paper defines the SMC-based proposed mathematical relations for different states. However, the alone use of this strategy cannot guarantee the operation of HESSs at optimal points. Generally, the previous studies have used three conditions of acceleration/ braking/stop as different vehicle movement states [26]. However, in the presented operation states of the vehicle, five states are defined based on the demand power $\left(P_{\text {Demand }}(t)\right)$, speed $(v(t))$, and acceleration $(a(t))$, as shown in Figure 2. These five vehicle movement states are idling, acceleration, fixed speeding cruise, braking, and regenerative braking. The vehicle movement states is formulated by (9) [27]:

$$
V S M(t)=\operatorname{sign}(a(t))+\operatorname{sign}(v(t))+\operatorname{sign}\left(P_{\text {Demand }}(t)\right)
$$




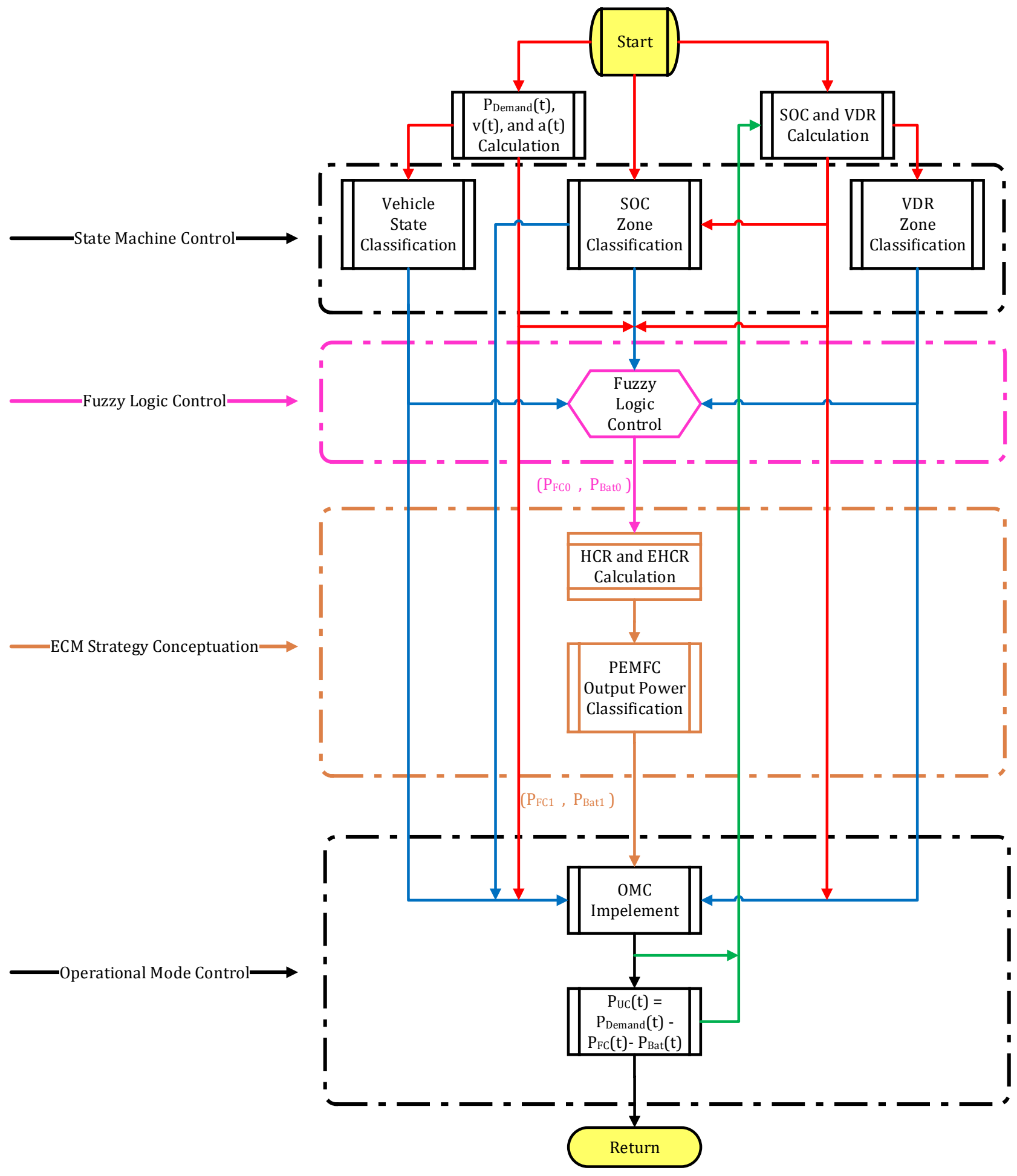

Figure 1. Multi-level EMS flowchart.

Furthermore, the optimal operation of the battery and UC depend on the charge/ discharge efficiency. In this study, battery combined efficiency $(B C E)$ and UC combined efficiency (UCE) are formulated to divide the different states of SOC and VDR. The battery combined efficiency of lead-acid battery $\left(\eta_{B C E}\right)$ is formulated in Table 1 and shown in Figure 3. 


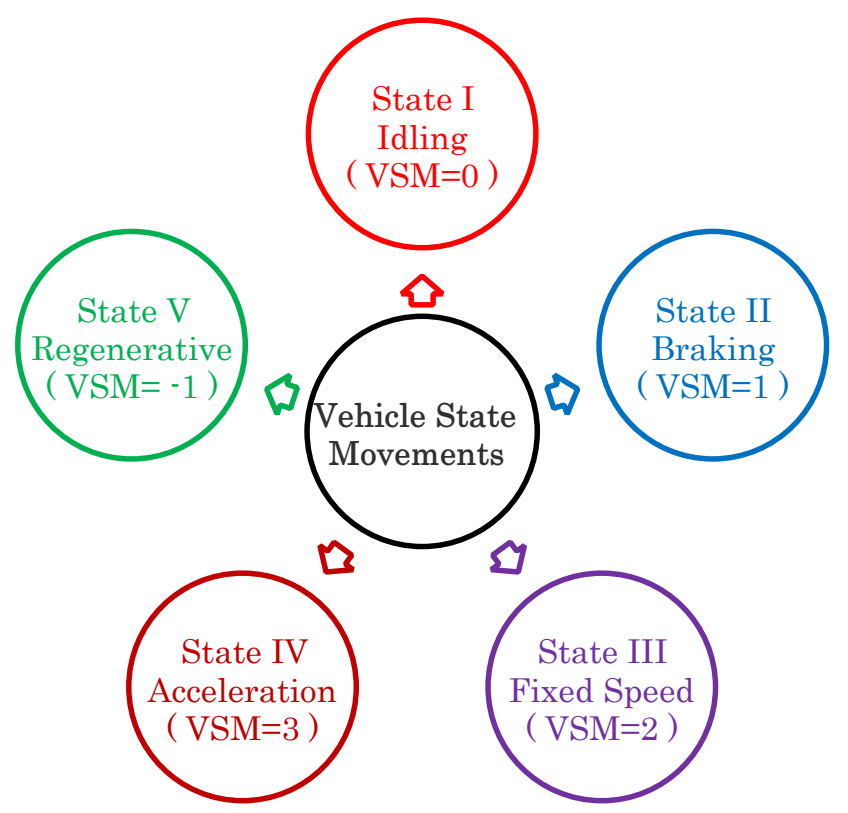

Figure 2. Vehicle state movement function values.

Table 1. The combined efficiency.

\begin{tabular}{ccc}
\hline Element & Combined Efficiency & Combined Efficiency Expectation \\
\hline Lead-acid battery & $\eta_{B C E}=\left(\frac{\eta_{\text {dis }}+\eta_{c h g}}{2}\right)$ & $\mu_{B C E}=\sum_{i=1}^{n} \eta_{i} P_{B C E}\left(\eta_{i}\right)$ \\
MAXWELL ultracapacitor & $\eta_{U C E}=\left(\frac{\eta_{u c d}+\eta_{u c c}}{2}\right)$ & $\mu_{U C E}=\sum_{i=1}^{n} \eta_{u i} P_{U C E}\left(\eta_{u i}\right)$ \\
\hline
\end{tabular}

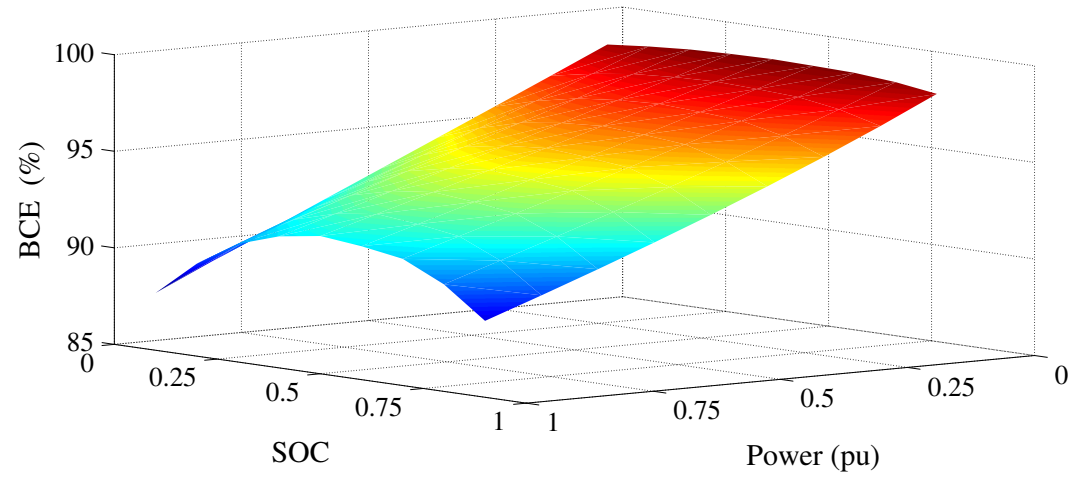

Figure 3. Typical Lead-acid battery combined efficiency.

In this study, $B C E$ is used to determine the different states of the battery SOC. The $B C E$ expectation $\left(\mu_{B C E}\right)$ is defined as Table 1 . However, more indices are required for dispersion analysis of BCE. The standard deviation is a proper index to determine the efficiency's dispersion from the median point. This index is calculated using by (10), in which uniform probability distribution function $\left(P_{B C E}\left(\eta_{i}\right)\right)$ is in the range of $[0.1,0.9]$.

$$
\sigma_{B C E}=\sqrt{E\left\{\left(B C E-\mu_{B C E}\right)^{2}\right\}}=\sqrt{\sum_{i=1}^{n}\left(\eta_{i}-\mu_{B C E}\right)^{2} P_{B C E}\left(\eta_{i}\right)}
$$

The battery combined efficiency, mean, and standard deviation for different SOCs of a lead-acid battery at rated power are shown in Figure 4. It can be seen that maximum BCE is $92.35 \%$ occurring when SOC is 0.5 ; minimum BCE is $88.31 \%$ occurring when SOC is 0.1 ; average $\mathrm{BCE}$ is $90.89 \%$; and the standard deviation of $\mathrm{BCE}$ is $1.42 \%$, which are used to divide states of the battery. 


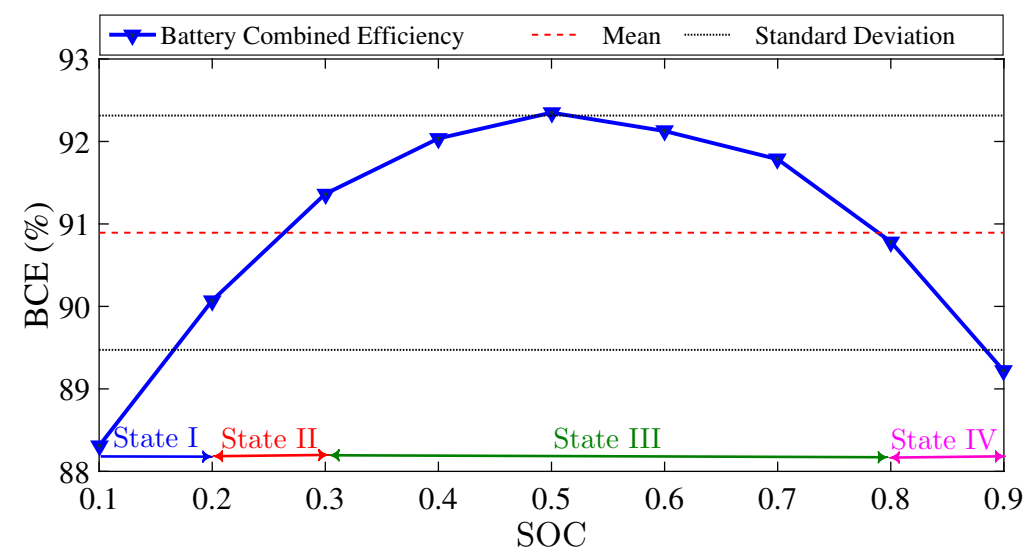

Figure 4. State division of Lead-acid battery based on BCE.

The high power density of UC discriminates it from other conventional ESSs and makes fast reactions in a short time possible. The charge/discharge efficiency of the UC depends on the voltage, current, and VDR. The UC combined efficiency can be used for analyzing the division of UC states. The mathematical calculations of UC combined efficiency are given in Table 1, and its curve is shown in Figure 5.

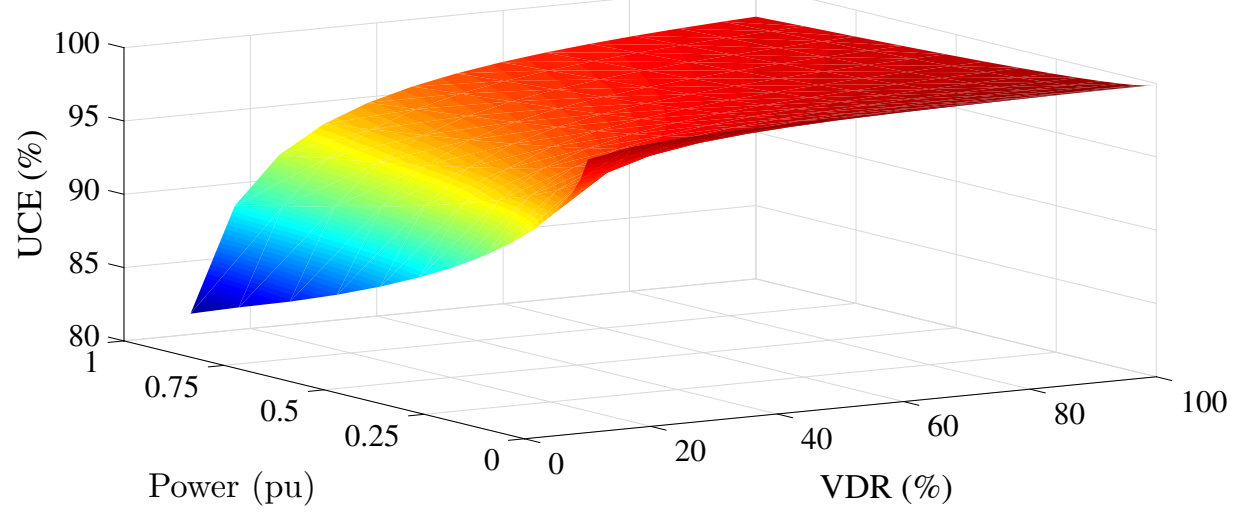

Figure 5. Typical MAXWELL ultracapacitor combined efficiency.

The expectation of the UC combined efficiency $\left(\mu_{U C E}\right)$ is defined as in Table 1, where uniform PDF $\left(P_{U C E}\left(\eta_{u i}\right)\right)$ is in the range of $[40,100]$. The UC combined efficiency at the rated power is divided into three operational regions as shown in Figure 6. It can be seen that as VDR is increased, UCE increases. The median of the combined efficiency is $95.2 \%$, and its average is $92.96 \%$ at the maximum power of $\mathrm{UC}$, which are used to separate the operational states of UC.

\subsection{Fuzzy Logic Control}

The deterministic rule-based methods are not adaptive. But fuzzy logic control can deal with multi-variable systems with uncertainties. The advantages of the proposed fuzzy logic in this paper are listed as follows: the FLC is used to reduce fluctuations of FC and battery output power; presented FLC reduces operational modes of the proposed EMS, and FLC Keeps battery SOC and UC VDR in the determined regions. The proposed FLC has defined with two outputs $\left\{P_{F C}, P_{B a t}\right\}$ and four inputs $\{$ demand power, SOC, VDR, VSM . The presented concepts for states are used to define SOC, VDR, and VSM trapezoidal membership functions. The complete data set of proposed fuzzy logic control can be found in [28]. The fuzzy subset of demand power is divided into (Low, Negative, Max, Medium, Zero\}; the fuzzy subset of SOC is divided into \{BHER, BLCR, BLER, BMER\}; and the fuzzy subset of VDR is divided into \{UHC, UHER, UMER\}. Instead of classifying driving cycles, 
the movement conditions of the vehicle are described using five linguistic trapezoidal terms, including $\{$ Acc, Brk, Id, Reg, Tra\}.

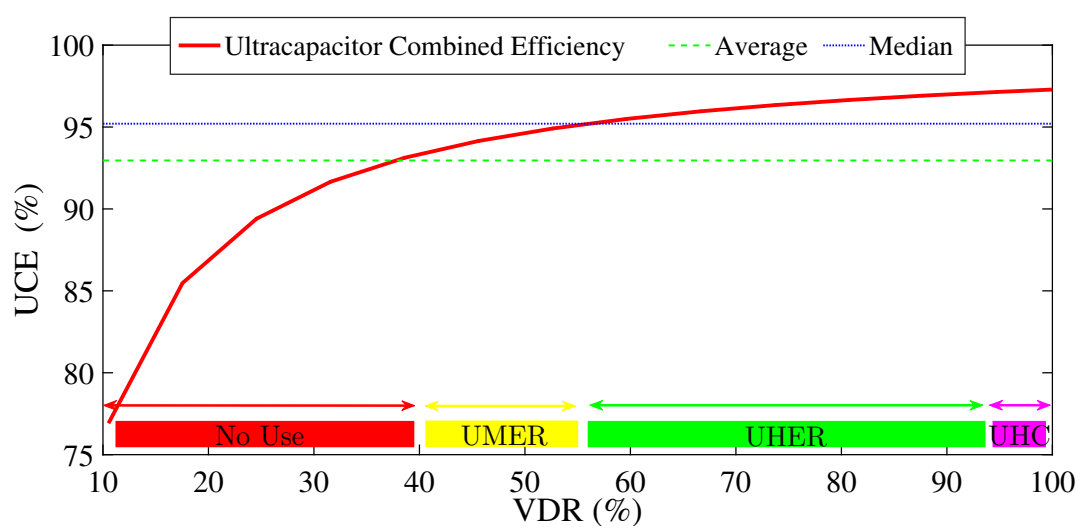

Figure 6. State division of UC based on UCE.

In this paper, the Mamdani inference procedure is used to design fuzzy supervisor. Furthermore, FC output power subsets are described using \{OFF, FCHER, FCP3, FCMER, FCP5, FCLER\}; and the battery output power subset is defined using $\{C h$, Zero, LD, MD, $\mathrm{HD}$ \}. In this paper, the FLC rules are formulated as "If inputs are $A_{i}$, Then outputs are $B_{i}$ ", and number of fuzzy rules are equal to $3 \times 4 \times 5 \times 5=300$. This FLC generates the initial reference value for the FC and battery output power, and the ECMS will be distributed the HESS power in the next step of proposed multi-level EMS.

\subsection{ECM Strategy Conception}

Currently, the FC output power change is an important problem that affects the PEMFC lifetime [29]. In this study, the operational modes of FC output power are determined based on HCR and equivalent hydrogen consumption. In this regard, the hydrogen consumption ratio is proposed to calculate the FC consumption per joule of energy. The HCR is formulated by (11). Then, the expectation and standard variation of HCR are calculated using (12) and (13) in which uniform $\operatorname{PDF}\left(P_{H}\left(H C R_{i}\right)\right)$ is in the range of $[0.17,1] p u$.

$$
\begin{gathered}
H C R=\frac{m_{H 2}}{P_{F C}}=\frac{\int_{0}^{t}\left[\frac{V_{F C}(t) i_{F C}(t)}{\eta_{d c}(t) \rho_{H 2}}\right] d t}{\int_{0}^{t} V_{F C}(t) i_{F C}(t) d t} \\
\mu_{H C R}=\int_{0.17}^{P_{F C}} H C R_{i} P_{H}\left(H C R_{i}\right) d\left(P_{F C}\right) \\
\sigma_{H C R}=\sqrt{\int_{0.17}^{P_{F C}}\left(H C R_{i}-\mu_{H C R}\right)^{2} P_{H}\left(H C R_{i}\right) d\left(P_{F C}\right)}
\end{gathered}
$$

The PEMFC HCR curve under various output powers is simulated and shown in Figure 7. Then six operational modes of the PEMFC are selected based on HCR and its mean, minimum, and standards deviation to prevent FC degradation and lifetime reduction, as shown in Figure 8. 


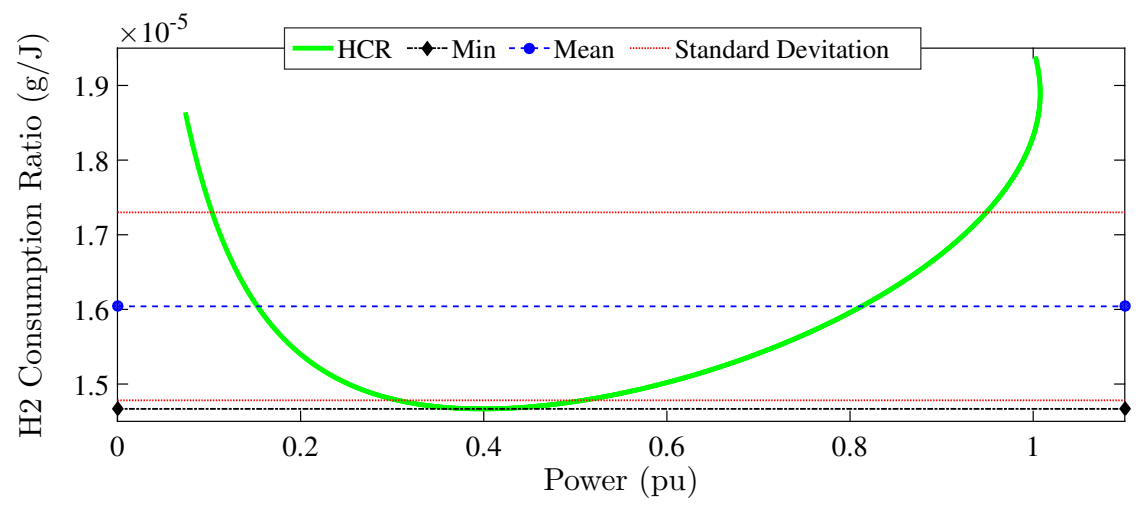

Figure 7. Hydrogen consumption ratio curve.

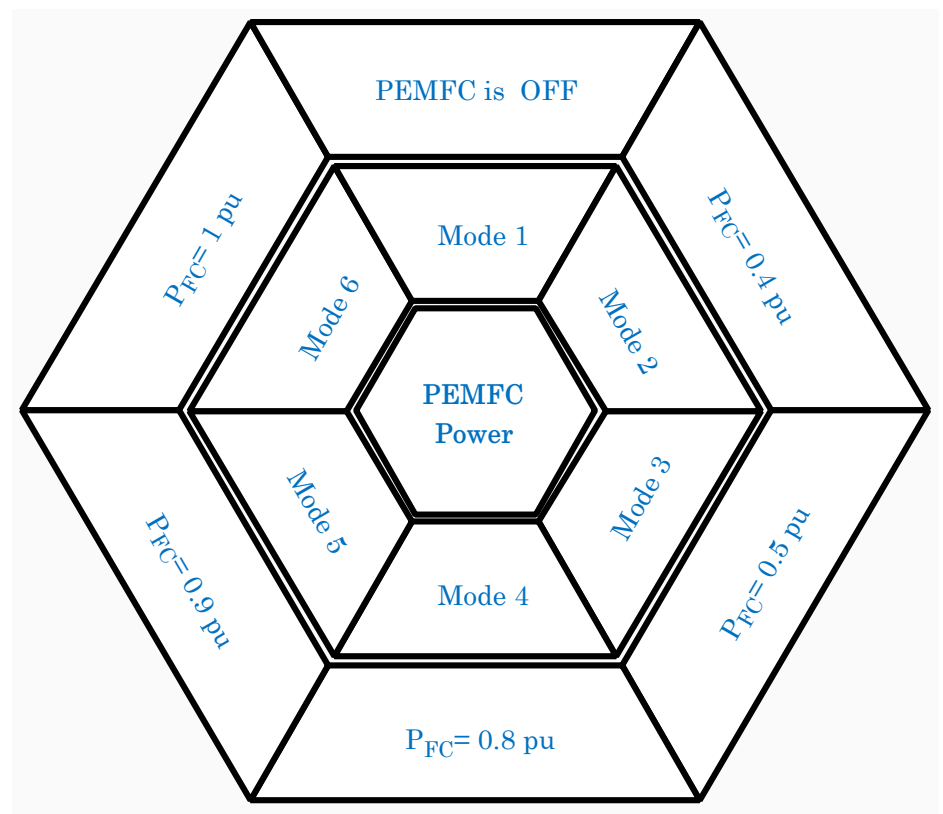

Figure 8. Operational modes of PEMFC based on HCR.

The state deviations of battery and UC (according to Figures 4 and 6) show that the UC combined efficiency is higher than the battery combined efficiency. Therefore, the BCE has a critical role in the equivalent hydrogen consumption ratio (EHCR). In this regard, the battery equivalent hydrogen consumption ratio $\left(E H C R_{B a t}\right)$ formulation is proposed based on (14), in which $\eta_{d c}$ is the efficiency of the bidirectional $D C-D C$ converter which is connected to the battery.

$$
E H C R_{B a t}=\frac{\Delta S O C \times E_{B a t} \times 3600}{\int_{0}^{t} V_{F C}(t) i_{F C}(t) d t \times \eta_{f c} \times \eta_{d c} \times \eta_{c h g} \times \rho_{H 2}}
$$

The battery equivalent hydrogen consumption ratio is evaluated to obtain the results of charging battery at the lowest equivalent hydrogen consumption per joule of energy. In the next step, EHCR will be considered to select the optimal operational modes of HESS.

\subsection{Operational Mode Control}

After ECMS idea formulation, the different operational modes of PEMFC and battery output power classifications into $0.5 \mathrm{~kW}$ intervals are used to reduce FC and battery power fluctuations. The proposed OMC is based on changes of the battery SOC, UC VDR, vehicle demanded power, and VSM, which tries to be used as follow: 
- The main priority of EMS is the PEMFC operation at a minimum hydrogen consumption ratio.

- The battery charging mode has been done for modes in which the PEMFC operates at the minimum HCR, and the equivalent hydrogen consumption at the present mode is lower than the HCR at the next mode $\left(E H C R_{\text {Bat }}^{(i)}<H C R^{(i+1)}\right)$.

- The battery discharging mode has been done in cases that the demanded power is higher than PEMFC output power, or the UC VDR is very low.

- During idling state, the FC with regarding SOC and VDR states can operate at $0.4 \mathrm{pu}$, and charge the battery and UC.

- If the demand power is higher than FC power, then the proposed OMC distributes demand power between HESS using results of the FLC method.

- When the vehicle is in the regenerative braking state, the FC is OFF. The battery is charged based on FLC output, and the UC captures regenerative braking energy as possible.

Therefore, the output modes of the proposed OMC are adjusted according to Table 2, in which $u$ is the step function, and, $P_{F C, o p t}, P_{B a t, o p t}$, and $P_{U C, o p t}$ is the optimal output power of the proposed EMS for FC, battery, and UC, respectively.

Table 2. Operational mode control rules.

\begin{tabular}{|c|c|}
\hline VSM & Output Mode Function \\
\hline $\mathrm{VSM}=-1$ & $\begin{array}{c}P_{F C, o p t}=0 \\
P_{\text {Bat }, o p t}=P_{\text {Bat } 1} \times u(0.5-S O C) \\
P_{U C, o p t}=P_{\text {Demand }}-P_{F C, o p t}-P_{\text {Bat }, o p t}\end{array}$ \\
\hline $\mathrm{VSM}=0$ & $\begin{array}{c}P_{F C, o p t}=0.4 \times u(0.8-S O C) \times u(98-V D R) \\
P_{\text {Bat }, \text { opt }}=P_{\text {Bat } 1} \times u(0.5-S O C) \\
P_{U C, \text { opt }}=P_{\text {Demand }}-P_{F C, o p t}-P_{\text {Bat }, \text { opt }} \\
\end{array}$ \\
\hline $\mathrm{VSM}=1$ & $\begin{array}{c}P_{F C, o p t}=P_{F C 1} \times u\left(P_{F C 1}-P_{\text {Demand }}\right) \times u(0.5-S O C) \times u(56-V D R) \\
+P_{F C 1} \times u\left(P_{\text {Demand }}-P_{F C 1}\right) \\
P_{\text {Bat }, o p t}=P_{\text {Bat } 1} \times u\left(P_{F C 1}-P_{\text {Demand }}\right) \times u(56-V D R) \\
+P_{\text {Bat } 1} \times u\left(P_{\text {Demand }}-P_{F C 1}\right) \\
P_{U C, o p t}=P_{\text {Demand }}-P_{F C, o p t}-P_{\text {Bat }, o p t}\end{array}$ \\
\hline $\mathrm{VSM}=2$ & $\begin{array}{c}P_{F C, o p t}=P_{F C 1} \times u\left(P_{\text {Demand }}-P_{F C 1}\right) \times u(95-V D R) \\
+P_{F C 1} \times u\left(P_{F C 1}-P_{\text {Demand }}\right) \times u(56-V D R) \\
P_{\text {Bat }, o p t}=P_{\text {Bat } 1} \times u\left(P_{F C 1}-P_{\text {Demand }}\right) \times u(56-V D R) \\
+P_{\text {Bat } 1} \times u\left(P_{\text {Demand }}-P_{F C 1}\right) \\
P_{U C, \text { opt }}=P_{\text {Demand }}-P_{F C, o p t}-P_{\text {Bat }, \text { opt }}\end{array}$ \\
\hline $\mathrm{VSM}=3$ & $\begin{array}{c}P_{F C, \text { opt }}=\min \left(P_{F C 1}(p u), 0.4\right) \times u\left(P_{F C 1}-P_{\text {Demand }}\right) \times u(V D R-95) \\
+\max \left(P_{F C 1}(p u), 0.4\right) \times u\left(P_{F C 1}-P_{\text {Demand }}\right) \times u(95-V D R) \\
+\max \left(P_{F C 1}(p u), 0.4\right) \times u\left(P_{\text {Demand }}-P_{F C 1}\right) \\
P_{\text {Bat }, o p t}=P_{\text {Bat } 1} \\
P_{U C, \text { opt }}=P_{\text {Demand }}-P_{F C, o p t}-P_{\text {Bat }, o p t}\end{array}$ \\
\hline
\end{tabular}

\section{Simulation Verification}

To verify the performance of proposed EMS compared to other strategies, the simulation framework is developed as shown in Figure 9, which includes FCHEV dynamic model, PEMFC model, battery model, UC model, and proposed EMS simulation platform. The characteristics of the FCHEV are listed in Table 3, and the simulation framework of online EMS includes FLC, levelization method based on ECMS, and proposed OMC strategy. According to Figure 9, the proposed EMS simulation platform consists of three consecutive stages. In the first step, FLC determines the output power of the fuel cell and the battery $\left(P_{F C 0}, P_{B a t 0}\right)$. The output power of the fuel cell and battery is levelized in the 
second stage $\left(P_{F C 1}, P_{B a t 1}\right)$. Finally, the operational mode control strategy in the third step calculates the desired output solutions $\left(P_{F C, o p t}, P_{B a t, o p t}, P_{U C, o p t}\right)$.
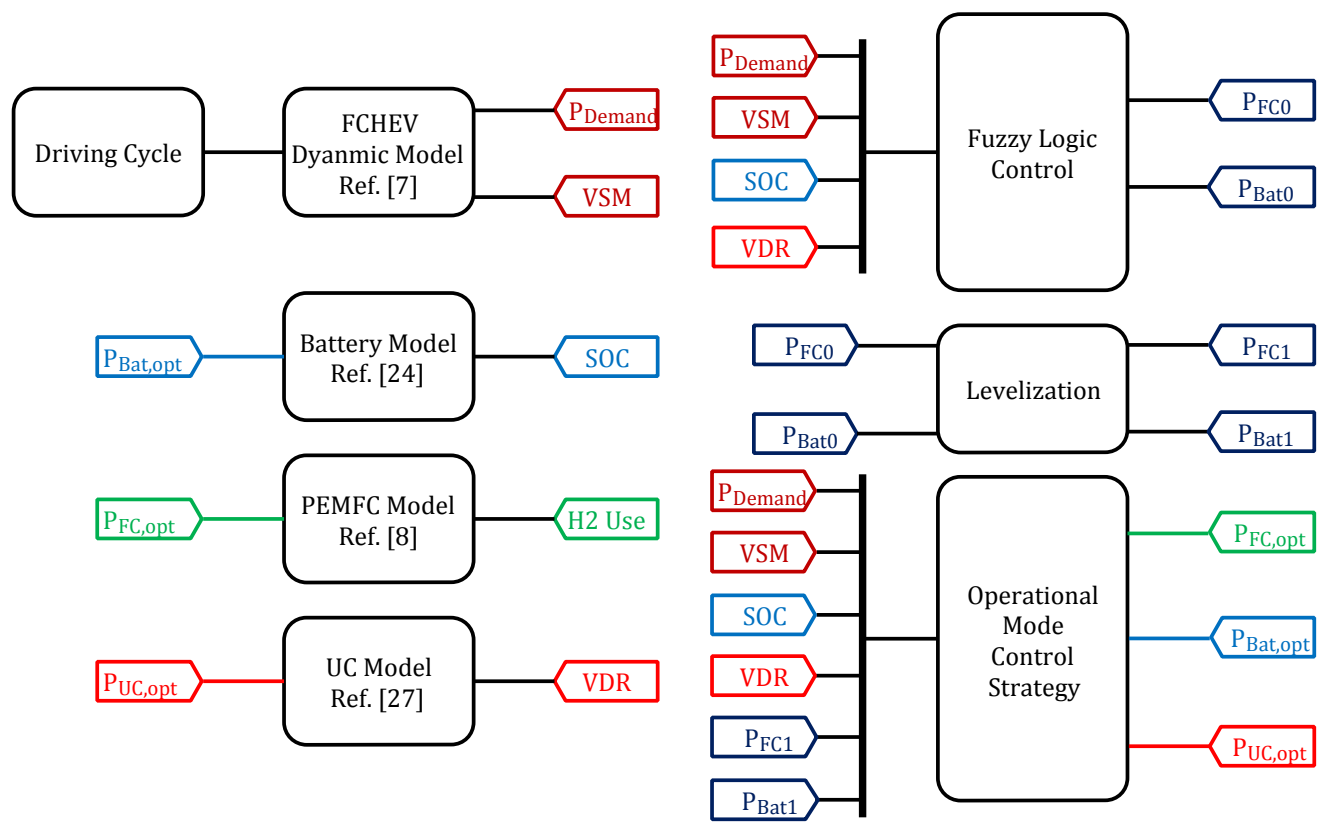

Figure 9. Simulation framework of the proposed EMS.

Table 3. FCHEV component specifications.

\begin{tabular}{cccc}
\hline FCHEV [19] & & & \\
Mass & $1500 \mathrm{~kg}$ & Front area & $2 \mathrm{~m}^{2}$ \\
Drive-train efficiency & $85 \%$ & Drag coefficient & 0.335 \\
\hline $\begin{array}{c}\text { Fuel cell system [19] } \\
\text { Type }\end{array}$ & PEM & Max power & $50 \mathrm{~kW}$ \\
Mass & $223 \mathrm{~kg}$ & Peak efficiency & $60 \%$ \\
\hline Battery [24] & & Max capacity & $36 \mathrm{Ah}$ \\
Type & Lead-acid & Module number & 13 \\
Rated voltage & $12 \mathrm{~V}$ & & \\
MAXWELL Ultracapacitor cell & & Rated capacitance & $3000 \mathrm{~F}$ \\
Type & $\mathrm{K} 2$ & Module number & 110 \\
Rated voltage & $2.7 \mathrm{~V}$ & &
\end{tabular}

To implement the proposed EMS in real-time conditions, the computational time of EMS running is an important subject. The running time of the fuzzy logic controller to provide a decision in the proposed EMS could be lengthy. Different driving scenarios and several input variables affect the output results of the FLC system. In order to solve this problem, the variable inputs are estimated for different scenarios and the fuzzy logic control system is executed offline for different scenarios at the first step, then the leveled output results for different scenarios are stored as a look-up table in the MATLAB/Simulink environment.

The input variables of VSM, SOC, and VDR in FLC include various discrete modes of vehicle status such as movement, battery, and ultracapacitor charge. The main and anonymous variable of FLC in online execution mode is $P_{\text {Demand }}$. According to the range of other input variables, the output scenarios of FLC in offline execution can be reduced. Accordingly, FLC output response evaluation is first investigated based on VSM discrete states, battery SOC, and UC VDR regions. In fact, for 60 different scenarios, the output response changes are simulated relative to the demanded power of the FCHEV. These output responses for 60 different scenarios can be classified. On the other hand, the proposed 
strategy according to Figure 1 levelizes the output power of FLC $\left(P_{F C 0}, P_{B a t 0}\right)$ and in fact the levelized output power $\left(P_{F C 1}, P_{B a t 1}\right)$ has a confined number of modes that can be saved as a look-up table. Thus, the running time of the FLC system has not caused any delay in the online performance of the proposed energy management strategy.

The EMS of FCHEV plays an important role in fuel consumption minimization and power fluctuations reduction. In this section, several driving cycles are applied to validate the proposed online multi-level EMS. In the first scenario, NEDC driving cycle is applied as an irregular terrain on FCHEV, and the performance of the EMS is verified in the simulation platform of MATLAB. Then results of the proposed online multi-level EMS under different driving cycles are used to compare its performance.

\subsection{EMS Results for NEDC Driving Cycle}

To verification, the simulation results of the proposed online multi-level EMS in the NEDC driving cycle for an FCHEV are presented in Figures 10-15. The NEDC driving cycle's demanded power is shown in Figure 10. The PEMFC output power is presented in Figure 11, where the maximum value of PEMFC output power is $0.8 \mathrm{pu}$. According to Figure 11, the PEMFC operates in the output power of 0.4 pu in most cases, which has the maximum efficiency. The lead-acid battery's output power is shown in Figure 12, where its maximum value is $4 \mathrm{~kW}$.

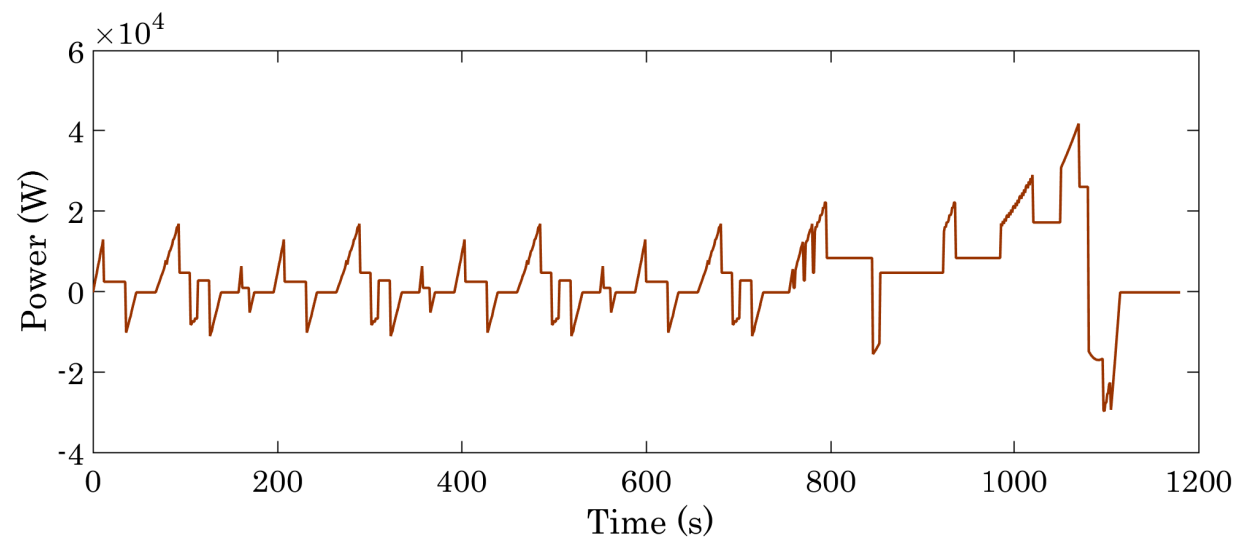

Figure 10. Demanded power of FCHEV in NEDC driving cycle.

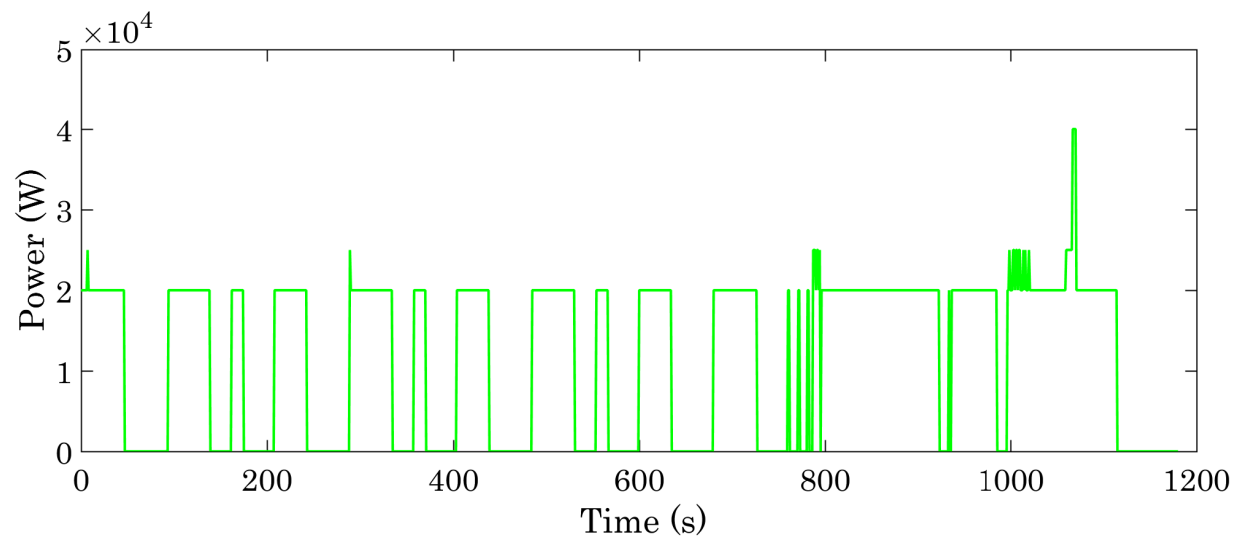

Figure 11. PEMFC power in NEDC driving cycle.

As can be seen, the lead-acid battery lifetime can be improved because of operating without fluctuations in most cases. The battery SOC is shown in Figure 13 to analyze charge/discharge performance and the difference between initial and final SOC values, which is $0.016 \%$. Figure 14 shows the UC output power in which the maximum required power is $22.15 \mathrm{~kW}$. According to Figures 10-15, the UC effectively can decrease the power fluctuations of PEMFC and battery. Also, it can be noticed that in the proposed EMS, UC 
is charged at the optimal point of the PEMFC. In addition, Figure 15 shows UC VDR in which the final value of VDR is $12.81 \%$ higher than the initial value of VDR. Results show that the proposed online multi-level EMS can be applied to improve the total efficiency of HESS, reduce PEMFC and lead-acid battery power fluctuations, and decrease the difference between initial and final SOC.

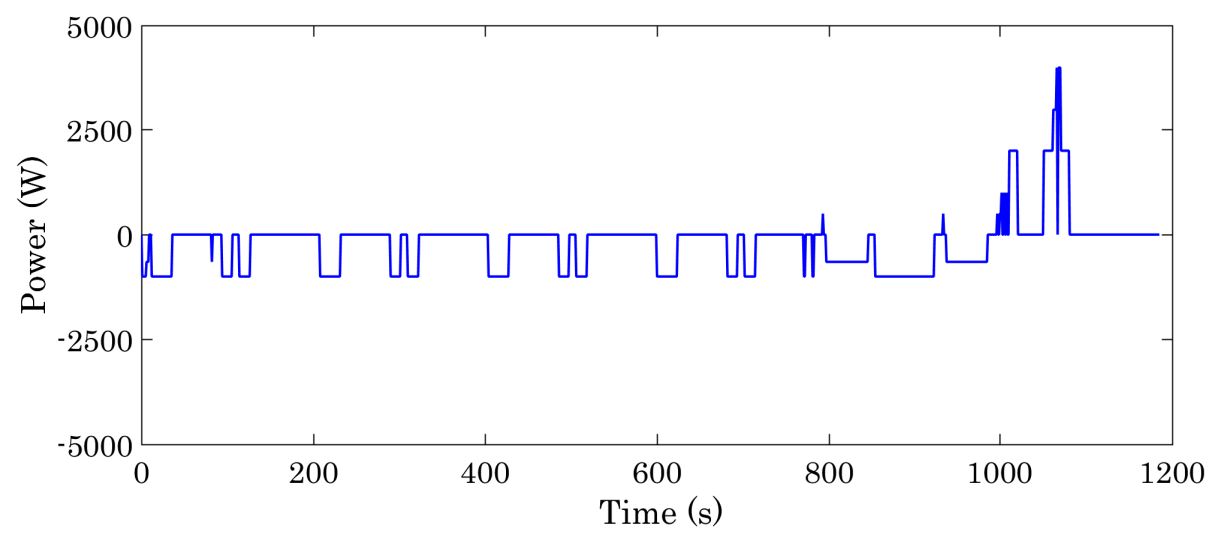

Figure 12. Battery power in NEDC driving cycle.

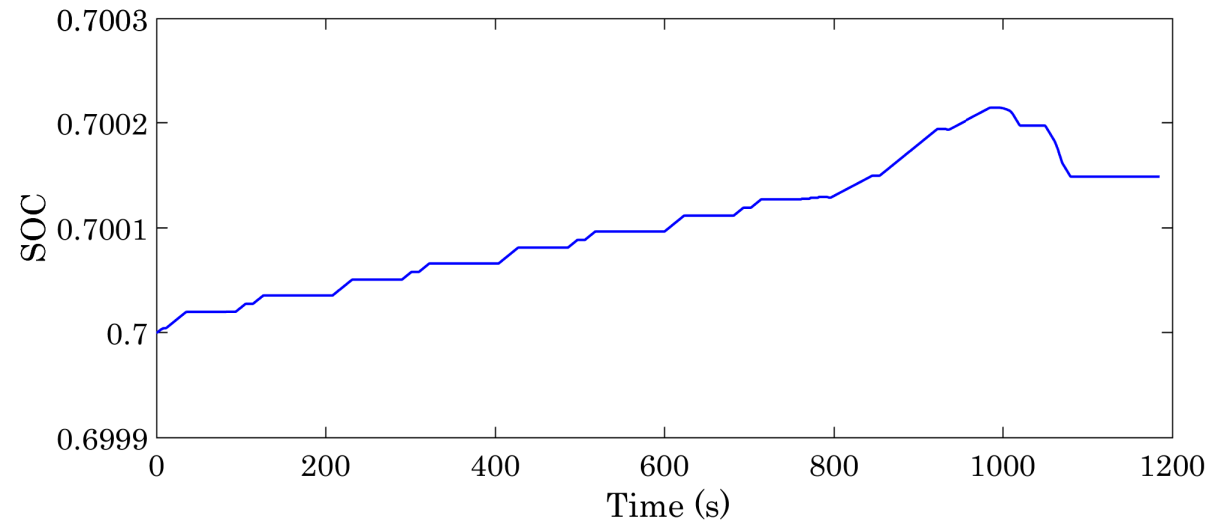

Figure 13. Battery SOC in NEDC driving cycle.

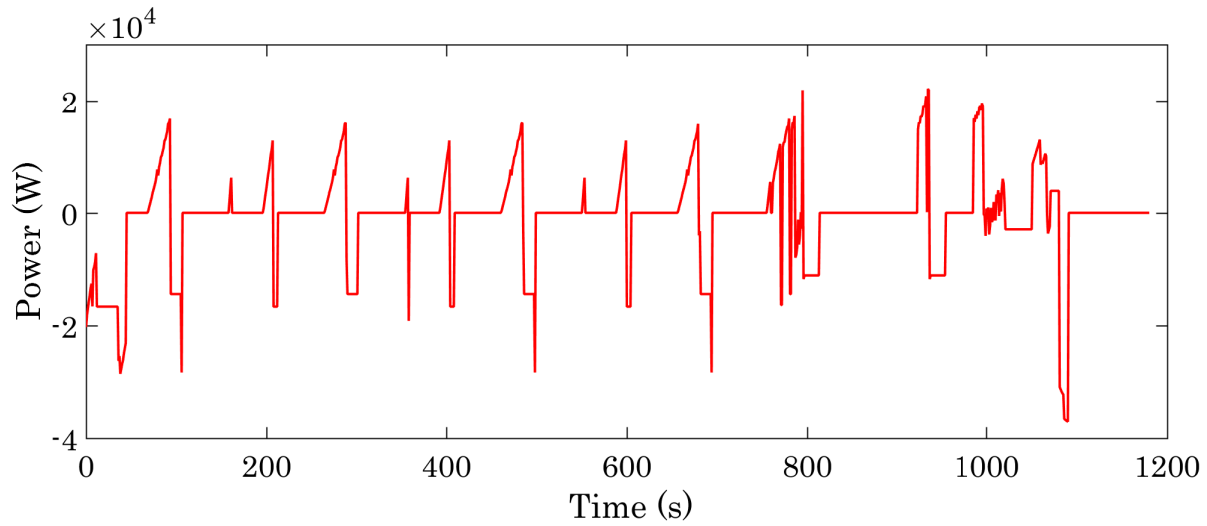

Figure 14. UC power under NEDC driving cycle. 


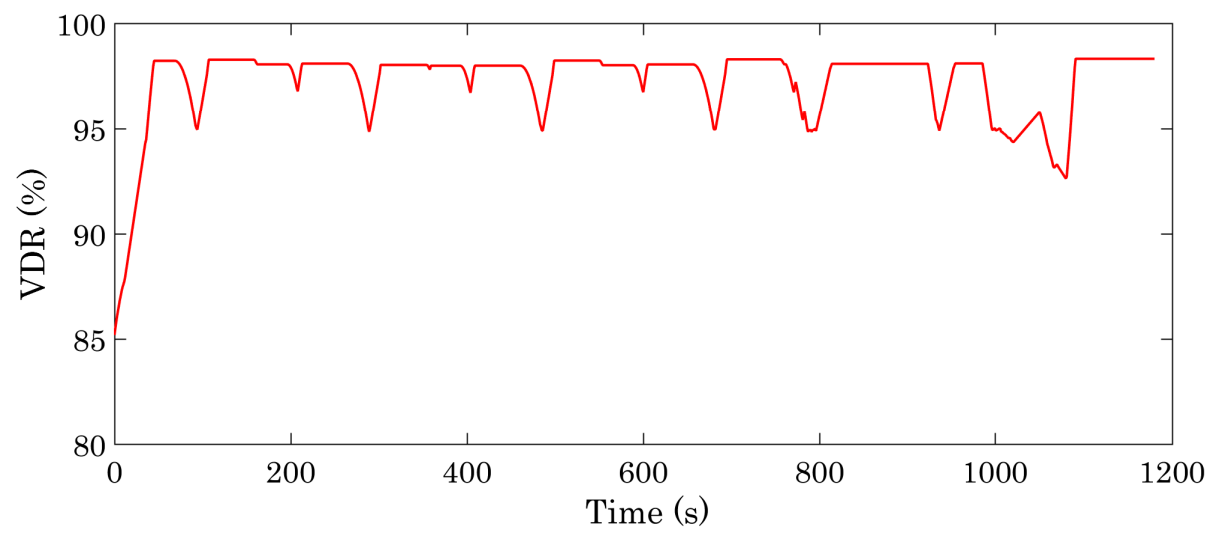

Figure 15. UC VDR under NEDC driving cycle.

\subsection{EMS Results Comparison}

To verification of proposed online multi-level energy management strategy, the obtained results are compared with Opt-FLC EMS presented in [19]. The results are demonstrated in Table 4 for these strategies over 6 different driving cycles. According to Table 4 , the results validate that proposed online multi-level EMS decreases the PEMFC fuel consumption, lead-acid battery power fluctuations, and $\triangle$ SOC. The fuel consumption in the proposed EMS is less than the Opt-FLC strategy; for instance, the proposed EMS consumes 4.37 MPG (miles per gallon) in the NEDC driving cycle, while the Opt-FLC strategy consumes 3.95 MPG. To study the proposed EMS's efficiency, the $\triangle$ SOCs under different driving cycles are presented in Table 4 . It is clear that the initial and final SOC has a minimum difference in the proposed EMS. Also, battery power fluctuations are listed in Table 4. According to Table 4, the PEMFC and battery power fluctuations have reduced in the proposed online multi-level EMS compared with the Opt-FLC strategy.

Table 4. EMS methods comparison.

\begin{tabular}{cccc}
\hline Driving Cycle & Compared Parameters & Opt-FLC EMS [19] & Proposed EMS \\
\hline \multirow{2}{*}{ (1) NEDC } & MPG & 3.95 & 4.37 \\
& $\Delta$ SOC & $+1.69 \%$ & $+0.01 \%$ \\
& Battery fluctuations & $1.840 \mathrm{~kW}$ & $0.709 \mathrm{~kW}$ \\
\hline \multirow{2}{*}{ (2) UDDS } & MPG & 4.00 & 6.36 \\
& $\Delta$ SOC & $-0.13 \%$ & $+0.010 \%$ \\
& Bat Fluc & $3.377 \mathrm{~kW}$ & $0.498 \mathrm{~kW}$ \\
\hline \multirow{3}{*}{ (3) HWFET } & MPG & 4.66 & 7.63 \\
& $\Delta$ SOC & $+0.02 \%$ & $+0.015 \%$ \\
& Battery fluctuations & $2.396 \mathrm{~kW}$ & $0.498 \mathrm{~kW}$ \\
\hline \multirow{3}{*}{ (4) EUDC } & MPG & 2.249 & 5.44 \\
& $\Delta$ SOC & $+1.34 \%$ & $+0.002 \%$ \\
& Battery fluctuations & $3.085 \mathrm{~kW}$ & $0.220 \mathrm{~kW}$ \\
\hline \multirow{3}{*}{ (5) LA92 } & MPG & 3.76 & 5.81 \\
& $\Delta$ SOC & $+0.04 \%$ & 0 \\
& Battery fluctuations & $3.621 \mathrm{~kW}$ & $0.825 \mathrm{~kW}$ \\
\hline \multirow{3}{*}{ (6) JP 10 Mode } & MPG & 3.08 & 3.23 \\
& $\Delta$ SOC & 0 & 0 \\
\hline
\end{tabular}

\section{Conclusions}

According to the previous studies presented in this work, energy management strategies were not analyzed based on the mathematical formulations to divide SOC and VDR 
regions. Many of the reviewed studies have used only three driving cycles to classify vehicle movement identification. Moreover, these power fluctuations reduction of FC and battery can be improved in comparison to the reviewed studies.

The proposed strategy in this paper recognizes the vehicle's dynamic movement conditions based on the VSM function's formulation. The combined efficiency of battery and UC is presented to divide SOC and VDR states based on mathematical relations. In an FC system, keeping the FC's operating point on the best output power is one of the most attractive ideas. In this study, the FC output power modes are calculated based on the HCR function to select six operating points to improve fuel consumption. Also, the battery output power modes are presented to reduce battery power fluctuations. These modes not only improve efficiency but also reduce fluctuations of the FC output power. Moreover, the battery SOC and the UC VDR are considered to determine the FC's operating point. Also, this paper identifies the vehicle's dynamic movement conditions accurately and uses them to determine the operational modes.

The proposed EMS performance is validated through six different driving cycles. The simulation results of the online multi-level EMS indicate that the UC is charged at the optimal operation point of the PEMFC so that it can increase the total efficiency of the HESS. Not only instantaneous fluctuations of the PEMFC output power are eliminated, but also it is not required to be operated at maximum power (minimum efficiency). The battery output power has fewer fluctuations compared to the Opt-FLC method. Therefore, its lifetime is prolonged. Finally, the simulation results confirmed that the multi-level EMS could reduce fuel consumption, decrease battery power fluctuations, and optimally control the HESS.

Although this article has well proven the performance of the proposed online EMS, a lifetime assessment of the HESS and state of health of the battery can be supposed to extend the scope of this paper. A future work of this article is to consider a model for optimizing the operational modes of HESS with machine learning methods to improve the fuel economy. Furthermore, comparing the results of the proposed VSM with results obtained from other driving condition identification methods can be an interesting subject for future studies.

Author Contributions: Conceptualization, H.F.G. and M.F.; Methodology, H.F.G. and M.F.; Software, H.F.G.; Validation, H.F.G. and M.F.; Formal analysis, H.F.G. and M.F.; Investigation, H.F.G. and M.F.; Data curation, H.F.G. and M.F.; Writing—original draft preparation, H.F.G.; Writing-review and editing, H.F.G. and M.F.; Visualization, H.F.G. and M.F. All authors have read and agreed to the published version of the manuscript.

Funding: This research received no external funding.

Institutional Review Board Statement: Not applicable.

Informed Consent Statement: Not applicable.

Data Availability Statement: Please see [28].

Conflicts of Interest: The authors declare no conflict of interest.

\section{References}

1. Biswas, A.; Emadi, A. Energy management systems for electrified powertrains: State-of-the-art review and future trends. IEEE Trans. Veh. Technol. 2019, 68, 6453-6467. [CrossRef]

2. Gharibeh, H.F.; Yazdankhah, A.S.; Reza Azizian, M.; Farrokhifar, M.; Alahyari, A. Impact Assessment of Installed Photovoltaic on Fuel Cell Hybrid Electric Vehicle Considering Fast Identification of Power Changes. In Proceedings of the 2020 International Youth Conference on Radio Electronics, Electrical and Power Engineering (REEPE), Moscow, Russia, 12-14 March 2020; pp. 1-6.

3. Banaei, M.; Rafiei, M.; Boudjadar, J.; Khooban, M.H. A comparative analysis of optimal operation scenarios in hybrid emission-free ferry ships. IEEE Trans. Transp. Electrif. 2020, 6, 318-333. [CrossRef]

4. Kollmeyer, P.J.; Wootton, M.; Reimers, J.; Opila, D.F.; Kurera, H.; Kadakia, M.; Gu, R.; Stiene, T.; Chemali, E.; Wood, M.; et al. Real-time control of a full scale Li-ion battery and Li-ion capacitor hybrid energy storage system for a plug-in hybrid vehicle. IEEE Trans. Ind. Appl. 2019, 55, 4204-4214. [CrossRef] 
5. Gharibeh, H.F.; Khiavi, L.M.; Farrokhifar, M.; Alahyari, A.; Pozo, D. Power Management of Electric Vehicle Equipped with Battery and Supercapacitor Considering Irregular Terrain. In Proceedings of the 2019 International Youth Conference on Radio Electronics, Electrical and Power Engineering (REEPE), Moscow, Russia, , 14-15 March 2019; pp. 1-5.

6. Lukic, S.M.; Cao, J.; Bansal, R.C.; Rodriguez, F.; Emadi, A. Energy storage systems for automotive applications. IEEE Trans. Ind. Electron. 2008, 55, 2258-2267. [CrossRef]

7. Gharibeh, H.F.; Yazdankhah, A.S.; Azizian, M.R. Improved energy management for a power-split multi-source fuel cell vehicle based on optimal source sizing and regenerative braking. In Proceedings of the 2016 IEEE 16th International Conference on Environment and Electrical Engineering (EEEIC), Florence, Italy, 7-10 June 2016; pp. 1-6.

8. Gharibeh, H.F.; Yazdankhah, A.S.; Azizian, M.R. Energy management of fuel cell electric vehicles based on working condition identification of energy storage systems, vehicle driving performance, and dynamic power factor. J. Energy Storage 2020, 31, 101760. [CrossRef]

9. Wang, T.; Li, Q.; Qiu, Y.; Yin, L.; Liu, L.; Chen, W. Efficiency extreme point tracking strategy based on FFRLS online identification for PEMFC system. IEEE Trans. Energy Convers. 2018, 34, 952-963. [CrossRef]

10. Li, Q.; Yang, W.; Yin, L.; Chen, W. Real-Time Implementation of Maximum Net Power Strategy Based on Sliding Mode Variable Structure Control for Proton-Exchange Membrane Fuel Cell System. IEEE Trans. Transp. Electrif. 2020, 6, 288-297. [CrossRef]

11. Wang, Y.; Sun, Z.; Chen, Z. Energy management strategy for battery/supercapacitor/fuel cell hybrid source vehicles based on finite state machine. Appl. Energy 2019, 254, 113707. [CrossRef]

12. Wang, Y.; Li, X.; Wang, L.; Sun, Z. Multiple-grained velocity prediction and energy management strategy for hybrid propulsion systems. J. Energy Storage 2019, 26, 100950. [CrossRef]

13. Lü, X.; Wu, Y.; Lian, J.; Zhang, Y.; Chen, C.; Wang, P.; Meng, L. Energy management of hybrid electric vehicles: A review of energy optimization of fuel cell hybrid power system based on genetic algorithm. Energy Convers. Manag. 2020, 205, 112474. [CrossRef]

14. Ali, A.M.; Ghanbar, A.; Söffker, D. Optimal Control of Multi-Source Electric Vehicles in Real Time Using Advisory Dynamic Programming. IEEE Trans. Veh. Technol. 2019, 68, 10394-10405. [CrossRef]

15. Huang, Y.; Wang, H.; Khajepour, A.; Li, B.; Ji, J.; Zhao, K.; Hu, C. A review of power management strategies and component sizing methods for hybrid vehicles. Renew. Sustain. Energy Rev. 2018, 96, 132-144. [CrossRef]

16. Zhou, D.; Al-Durra, A.; Gao, F.; Ravey, A.; Matraji, I.; Simoes, M.G. Online energy management strategy of fuel cell hybrid electric vehicles based on data fusion approach. J. Power Sources 2017, 366, 278-291. [CrossRef]

17. Sellali, M.; Betka, A.; Drid, S.; Djerdir, A.; Allaoui, L.; Tiar, M. Novel control implementation for electric vehicles based on fuzzy-back stepping approach. Energy 2019, 178, 644-655. [CrossRef]

18. Geng, C.; Jin, X.; Zhang, X. Simulation research on a novel control strategy for fuel cell extended-range vehicles. Int. J. Hydrogen Energy 2019, 44, 408-420. [CrossRef]

19. Ahmadi, S.; Bathaee, S.; Hosseinpour, A.H. Improving fuel economy and performance of a fuel-cell hybrid electric vehicle (fuel-cell, battery, and ultra-capacitor) using optimized energy management strategy. Energy Convers. Manag. 2018, 160, 74-84. [CrossRef]

20. Li, Q.; Su, B.; Pu, Y.; Han, Y.; Wang, T.; Yin, L.; Chen, W. A state machine control based on equivalent consumption minimization for fuel cell/supercapacitor hybrid tramway. IEEE Trans. Transp. Electrif. 2019, 5, 552-564. [CrossRef]

21. Li, Q.; Yang, H.; Han, Y.; Li, M.; Chen, W. A state machine strategy based on droop control for an energy management system of PEMFC-battery-supercapacitor hybrid tramway. Int. J. Hydrogen Energy 2016, 41, 16148-16159. [CrossRef]

22. Wang, T.; Li, Q.; Yin, L.; Chen, W. Hydrogen consumption minimization method based on the online identification for multi-stack PEMFCs system. Int. J. Hydrogen Energy 2019, 44, 5074-5081. [CrossRef]

23. Wang, Y.; Zhang, X.; Liu, C.; Pan, R.; Chen, Z. Multi-timescale power and energy assessment of lithium-ion battery and supercapacitor hybrid system using extended Kalman filter. J. Power Sources 2018, 389, 93-105. [CrossRef]

24. Hong, Z.; Li, Q.; Han, Y.; Shang, W.; Zhu, Y.; Chen, W. An energy management strategy based on dynamic power factor for fuel cell/battery hybrid locomotive. Int. J. Hydrogen Energy 2018, 43, 3261-3272. [CrossRef]

25. Rufer, A. Energy Storage: Systems and Components; CRC Press: Boca Raton, FL, USA, 2017.

26. Mebarki, N.; Rekioua, T.; Mokrani, Z.; Rekioua, D.; Bacha, S. PEM fuel cell/battery storage system supplying electric vehicle. Int. J. Hydrogen Energy 2016, 41, 20993-21005. [CrossRef]

27. Gharibeh, H.F.; Yazdankhah, A.S.; Azizian, M.R.; Farrokhifar, M. Online Energy Management Strategy for Fuel Cell Hybrid Electric Vehicles with Installed PV on Roof. IEEE Trans. Ind. Appl. 2021. [CrossRef]

28. Gharibeh, H.F.; Yazdankhah, A.S.; Farrokhifar, M. Online Multi-Level Energy Management Strategy Based on Rule-Based and Optimization-Based Methods for Fuel Cell Hybrid Electric Vehicles-Fuzzy Logic Data Sets. 2020. Available online: https: / / drive.google.com/drive/folders/1GdDC49B6HAAatV4T8EL03ItRatm_dsq3 (accessed in 1 March 2020).

29. Zhou, W.; Yang, L.; Cai, Y.; Ying, T. Dynamic programming for new energy vehicles based on their work modes Part II: Fuel cell electric vehicles. J. Power Sources 2018, 407, 92-104. [CrossRef] 